\title{
Effects of sitting posture modification and exercises in school going children with neck pain in rural area in Tamil Nadu
}

\author{
Perooru Rupesh ${ }^{\dagger}$, Malarvilzhi D, Prasanth D, Sivakumar VPR
}

\begin{abstract}
Background: Correct sitting posture reduces the risk of slouched posture, protruded chin and prevents the neck pain from disability.

Objective: The study was to determine the effect of postural correction exercises in rural area school going children. Methodology

Design quasi experimental design, 25subjects, age group10-14 years with neck pain from government high school\& talent high school, vellithiruppur, Erode, Tamil Nadu. Interventions were subjects received sitting posture modification and home care exercise advices (Isometric neck exercises, free exercises and postural correction) for 3 weeks. Outcome measures were Neck disability index and Visual analogue scale.
\end{abstract}

Results: Results obtained are NDI- Pre-test Mean, S.D $21.8 \pm 0.825688$; Post-test Mean, S.D 0.020618 , VAS- Pre-test Mean, S.D $04.9 \pm 1.986503$; Post-test Mean, S.D $01.4 \pm 0.026543$ shows there was significance difference between pre-test; post test data for NDI and VAS.

Conclusion: There was significant reduction in neck pain and neck disability after postural correction and exercises in school going children with neck pain in rural area.

\section{Keywords}

Neck pain, Neck Disability Index, Postural modification and Home care advices

\section{Introduction}

Children spend a considerable part of their daily life in school; spend about $80 \%$ of their school time in the classroom, performing various activities like reading and other related activities, which require them to sit on floor continuously for long hours in rural areas [1]. School children are at special risk of suffering neck pain due to the prolonged periods of poor postural habits.

The students of the secondary schools use benches and desks in classroom. However especially in rural areas, the students used to sit on the floor, due to infrastructural limitations as well as to maintain the traditional custom. Neck pain is increasingly prevalent among the rural area school going children. Estimation of $67 \%$ of individuals will suffer neck pain at some stage of their life [1].

Neck pain is a significant health problem not only for adults but also for the young. Long duration of sitting posture is associated with prolonged periods of holding a static posture, which is most pronounced, in sitting with forward head posture. Forward neck flexion may result in, increased tension in posture, muscles stabilizing neck increases the compressive force in the cervical spine. The main aim is to find 
out the effect of sitting postural correction and exercises in school going children with neck pain in rural area [2].

Neck pain usually arises because of any diseases in cervical spine and soft tissues around the neck. Muscular pain can be due to spasm of muscles caused by any injury, falling asleep in awkward position or prolonged poor positioning of neck. If this spasm is for a prolong period, it becomes chronic pain. Neck pain should be identified earlier and treated by posture correction and exercises to avoid complications. Forward head posture and flexion of the trunk are the main components of slumped sitting which changes the cervical alignment where the head and trunk are held forward relative to the lumbopelvic region. A flexed spine results in increased activity in cervical erector spinae, trapezius and thoracic erector spinae muscles. There is evidence linking prolonged trunk flexed posture with increased muscle loading and a subsequently increased risk for symptoms in the upper body [3].

Isometric exercises are a static form of exercises in which a muscle contracts and produce a force without appreciable change in the length of the muscle and without visible joint motion. Although there is no mechanical work done a measureable amount of tension and force output are produced by the muscle. Sources of resistance for isometrics exercise include holding against a force applied manually, holding a weight in a particular position, maintaining a position against the resistance of body weight, or pushing or pulling an immovable object. The pain which aggravates because of the impaired posture due to mechanical stress which is produced in the ligaments, facet capsules, periosteum of the vertebrae, muscles, anterior dura mater, dural sleeves, epidural areolar adipose tissue and walls of blood vessels are innervated and responsive to nociceptive stimuli. Mechanical stress to painsensitive structures, such as sustained stretch to ligaments or joint capsule or compression of blood vessels, causes distension or compression of the nerve endings, which leads to the experience of pain [4].

A forward head involves increased flexion of the lower cervical and the upper thoracic regions, increased extension of the upper cervical vertebra, extension of the occiput on first cervical vertebra. A forward neck posture leads to stress in the anterior longitudinal ligaments in the upper cervical spine and posterior longitudinal ligament in the lower cervical and thoracic spine, fatigue of the thoracic erector spinae and scapular retractors muscles and impingement of the cervical plexus from elevator scapulae muscle tightness. Good alignment may be prevented because of restricted mobility of muscle or connective tissue or mal alignment of a vertebral segment, but developing a awareness of balanced posture and its effects should begin as soon as possible in the treatment program. The aim of this study to find out the effects of sitting posture modification and exercises in school going children with neck pain in rural area [4].

\section{Methodology}

The Study design was Quasi Experimental design, Sampling method used to select subjects was Convenient sampling, Sample size obtained was 25 Students (21 boys and 04 girls), Study duration was 3 weeks program, study setting was taken at Government high school and Talent high school, Vellithiruppur, Erode, Tamil Nadu. The inclusion criteria were age group of 10-14 years, Both boys \& girls who complaints of neck pain, with visual analogue scale (VAS) scoring between 2 to 6 , Students with neck disability index (NDI) Score between 20 to 25. Exclusion criteria were any recent history of fractures in cervical spine, congenital or acquired deformity or contractures (Torticolis), history of neurological deficits and cardio vascular problems, cognitive impairment. Institutional Ethical Committee approval was obtained before starting the study and informed consent was taken from56 subjects (Students with neck pain) were given the Neck Disability Index and explained to fill the questionnaire (Scoring out of 40) with supervision of the therapist. Among that, 25 subjects those who met the inclusion and exclusion criteria followed by Visual Analogue Scale was explained and noted from the subjects with NDI score 20 to 25. PRE test values of NDI and VAS were taken. Subjects were positioned in Sitting, Position of therapist was standing, procedure for strengthening of neck, isometric exercises were given to the students and instructed to perform three times a day for 3 weeks, during end of alternate class hours i.e. 5 Repetitions $\times 3$ Sets / Session (*If increased pain or discomfort, stop and call your health care provider). Postural correctionduring the class hours the students were instructed to correct their sitting posture and sit erect. The above corrective exercises have taught to class teachers, and instructed to supervise and take precaution while students were performing. Free Exercises such as neck Range of Motion 


\section{Effects of sitting posture modification and exercises in school going children Review with neck pain in rural area in Tamil Nadu}

Exercises (for Better Blood Flow and Flexibility) like forward bending, sideways bending and rotations, for forward bending stand or sit, place hands behind your neck and gently tilt your neck forward looking down, sideways bending stand or sit, keep spine straight with face forward slowly tip ear towards shoulder to bring head back to starting position and switch sides, for rotations stand or sit, keep spine straight with face forward and gently turn head to the left bring head back to starting position and switch sides.

\section{- Exercises to strengthen the muscles}

For shoulder shrugging stand, keep spine straight relax shoulders at side and then raise shoulders toward ears and leave down,for chin tuck-in stand or sit, keep spine straight pull head straight back and then do not tip or move jaw. All exercises for 5 Repetitions for 3 Sets.

\section{n Postural correction exercise position}

The students were explained about the procedure. Students were given a copy of postural correction guidelines, Poor posture habits - Do not slouch, sit upright. Students asked to sit erect and maintain the neck position. After the intervention for 3 weeks, the NDI and VAS were taken [5]. Outcome measures for data collection used are Neck Disability Index and Visual Analogue Scale. Post-test measures were taken after 3 weeks.

\section{Results}

Paired sample ' $t$ ' test values were used for statistical analysis for pre and post-test values (Tables 1-3).

\section{Discussion}

This study shows that, participation in a three week neck strengthening program and postural correction led to a considerable reduction in the average neck pain, disability and improvement of neck muscle power in the students who performed neck exercises (Figure 1). The strength training might be an effective means to strengthen the neck and decrease injury risk [6]. The investigation associations between categories of response to neck pain/discomfort and the endurance time of neck muscles, neck range of motion, and neck and head morphology, sensitization or stretch effects arising from repeating endof-range measurements, and self-report data Isometric Neck Exercises Versus Dynamic Neck Exercises In Chronic Neck Pain from neck pain and disability questionnaires. The affective dimension of Neck Disability Index scores were significantly higher by subjects who had sought treatment than those of the untreated groups. The need for postural education and exercises were emphasized to children who adopts incorrect sitting positions during study times in schools. In addition unhealthy behaviors can trigger postural alteration [7]. Observing the efficacy of exercises and postural correction intervention in reducing neck pain, the present study aimed at combining both these interventions to explore if exercises together with ergonomic intervention proved to be more beneficial for neck pain in the students. Following intervention the severity and incidence decreased for pain and disability. The students appreciated the ability to overcome the disabling effects of wrong posture and lack of physical exercise. This study confirmed that selective neck exercises improved school student's posture and significantly enhanced the strength of their neck. The level of reduction in pain was significantly shown; this is explained by research on mechanisms of pain reduction through exercises. The increase in endorphins that occurs after training and better neuromuscular control may decrease pain. Muscle contractions activate muscle ergoreceptor (stretch receptors). Afferent from this muscle cause endogenous options to be released and also the beta endorphins from the pituitary gland. This secretion may cause both peripheral and central pain to be blocked [8]. Neck exercises may allow the musculo-tendinous proprioceptors to down grade their stretch reflex responses using operant conditioning techniques and multiple practice sessions. The intrafusal

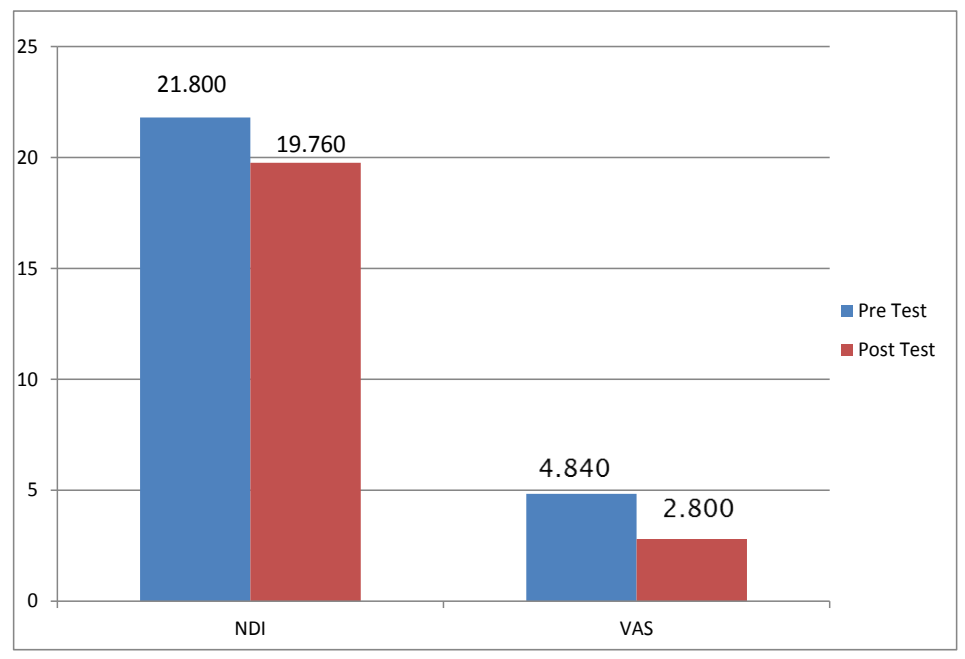

Figure 1: Pre and Post Test of NDI and VAS 
Table 1: Pre-Test values for NDI and VAS.

\begin{tabular}{|c|c|c|c|c|}
\hline Variables & Mean & Number & Standard Deviation & Standard Error Mean \\
\hline NDI & 21.80 & 25 & 1.44 & 0.28 \\
\hline VAS & 4.80 & 25 & 1.31 & 0.26 \\
\hline
\end{tabular}

\section{Table 2: Post Test values for NDI and VAS.}

\begin{tabular}{|c|c|c|c|}
\hline Variables & Mean & Number & Standard Deviation \\
\hline NDI & 19.76 & 25 & 1.89 \\
\hline VAS & 2.80 & 25 & 0.37 \\
\hline
\end{tabular}

\section{Table 3: Paired Sample Correlations.}

\begin{tabular}{|c|c|c|c|}
\hline Variables & Number & Correlation & Significance \\
\hline NDI Pre \& Post Test & 25 & 0.43 & 0.02 \\
\hline VAS Pre \& Post Test & 25 & 0.91 & 0.00 \\
\hline *There is significance difference between pre and posttest values. & \\
\hline
\end{tabular}

\section{Table 4: Paired Sample Test Values.}

\begin{tabular}{|c|c|c|c|c|c|c|c|c|}
\hline \multirow{2}{*}{ Paired Samples } & \multicolumn{4}{|c|}{ Variable Differences } & \multirow{2}{*}{$\begin{array}{c}\text { 95\% confident } \\
\text { interval of } \\
\text { differences }\end{array}$} & \multirow[b]{2}{*}{$\mathbf{t}$} & \multirow[b]{2}{*}{ Df } & \multirow[b]{2}{*}{ Sig- 2 tailed } \\
\hline & MEAN & SD & SED & LOWER & & & & \\
\hline $\begin{array}{c}\text { NDI PRE \&POST } \\
\text { TEST }\end{array}$ & 2.04 & 1.81 & 0.36 & 1.29 & 2.78 & 5.62 & 24 & 0.00 \\
\hline $\begin{array}{c}\text { VAS PRE \& POST } \\
\text { TEST }\end{array}$ & 2.04 & 0.93 & 0.18 & 1.65 & 2.42 & 10.91 & 24 & 0.00 \\
\hline
\end{tabular}

fibers may be reset, discontinuing the cycle of muscle tension, impaired circulation with metabolite accumulation and pain associated with myogenic (myofascial) pain. The exercises were designed for increasing the strength, endurance, and mobility of neck within an ample time period $[9,10]$.

\section{Conclusion}

The study concluded that there was significant reduction in neck pain and neck disability after postural correction and exercises. Clinical implications are prevention is better than cure, after every alternate hour recommend doing exercises, instructed to the class teachers and stressing the children to do neck exercises in rural area. Recommendations and limitations were, studies have to be done to compare both genders (boys and girls) and Rural versus Urban areas, further studies can be done with different age group and different occupations. The limitations of the study were sample size was less, range of motion (ROM) was not measured, and number of sitting posture hours were not considered, control group was not taken.

\section{References}

1. Conley MS, Meyer RA, Bloomberg JJ, et al. Noninvasive analysis of human neck muscle function. Spine (Phila Pa 1976) 20(23), 2505-2512 (1995).

2. Ariëns $G A$, Bongers $P M$, Dowes $M$, et al. Are neck flexion, neck rotation, and sitting at work risk factors for neck pain? Occup. Environ. Med 58(3), 200-207 (2001).

3. Hün囚ting W, Grandjian E, Maeda K, et al. Constrained postures in accounting machine operators. Appl. Ergon 11(3), 145149 (1980).

4. Kurumatani N, Iki M, Katagi K. Occupational cervicobrachial disorder
(OCD) of nursery school teachers based on subjective symptoms related to OCD. Sangyo. Igaku 26(5), 389-396 (1984).

5. Thorén $P$, Floras $J S$, Hoffmann $P$, et al. Endorphins and Exercise- Physiological mechanism and clinical implication. Journal of Medical Science Sports Exercise, 1990, 22(4), 417-428.

6. Hutton RS and Atwater SW. Acute and chronic adaptation of muscle proprioceptors in response to increased use. Sports. Med 14(6), 406-421 (1992).

7. Chiu TT and Lam PK. The prevalence of and risk factors for neck pain and upper limb pain among secondary school teachers in Hong Kong. J. Occup. Rehabil 17(1), 19-32
(2007).

8. Grimes P and Legg S Musculoskeletal Disorders (MSD) in school students as a risk factor for adult MSD: a review of the multiple factors affecting posture, comfort and health in classroom environments. J. Hum. Environ. Syst 7(1), 1-9 (2004).

9. Sullivan SB, Schmitz TJ. Physical Rehabilitation: Assessment and Treatment. 4th edition, Philadelphia. F. A. Davis Co., 2010-2015 (2001).

10. Watson DH and Trott PH. Cervical headache: an investigation of natural head posture and upper cervical flexor muscle performance. Cephalalgia, 13(4), 272-284 (1993). 